\title{
UPAYA MENURUNKAN TINGKAT KEMISKINAN MELALUI PENINGKATAN KAPASITAS KELOMPOK MASYARAKAT DI KABUPATEN LOMBOK BARAT PROPINSI NUSA TENGGARA BARAT
}

\author{
IDA BAGUS EKA ARTIKA ${ }^{1)}$, I WAYAN KEMBARYANA ${ }^{2)}$, \\ IDA AYU KETUT MARINI $\left.\right|^{3)}$, IDA AYU NOPIARI ${ }^{4)}$
}

\author{
${ }^{1,2)}$ Program Studi Ekonomi Kampus Mataram UNMAS Denpasar \\ ${ }^{3.4)}$ Program Studi Agribinis Kampus Mataram UNMAS Denpasar \\ e-mail: ${ }^{1)}$ guseka960@gmail.com, ${ }^{2)}$ yankembaryana@gmail.com, \\ 3)yumar4565@gmail.com, ${ }^{4)}$ queen_pino@yahoo.co.id
}

\begin{abstract}
ABSTRAK
Strategi penanggulangan tingkat kemiskinan merupakan strategi yang menjadi prioritas utama setiap pemerintah daerah di Indonesia saat ini, untuk mempercepat pengentasan kemiskinan menuju masyarakat yang sejahtera. Propinsi Nusa Tenggara Barat merupakan salah satu propinsi yang tingkat kemiskinannya masih di atas rata-rata nasional, sehingga diperlukan berbagai upaya percepatan pengentasan kemiskinan agar bisa mengejar ketertinggalan dari daerah lain. Penelitian ini dilakukan terhadap 3 kelmompok masyarakat,yaitu kelompok masyarakat petani peternak, kelompok masyarakat nelayan dan kelompok masyarakat perajin di 3 desa Lombok Barat, dengan melakukan analisis SWOT dalam rangka menemukan strategi yang tepat untuk mempercepat pengentasan kemiskinan, khususnya di kabupaten Lombok Barat.

Hasil penelitian menemukan bahwa diperlukan strategi untuk mennggulangi kelemahan yang ada pada kelompok masyarakat, untuk mendapatkan peluang-peluang pemberdayaan masyarakat yang ada. Programprogram yang perlu dilakukan adalah program peningkatan kapasitas kelompok melalui pendampingan untuk mendapatkan program pemberdayaan oleh pemerintah, program peningkatan kapasitas kelompok untuk mendapatkan akses perbankan guna menambah modal usaha kelompok, dan program penguatan kelembagaan kelompok masyarakat dengan menjadikan kelompok masyarakt sebagai koperasi berbadan hokum untun memudahkan pihak pemerintah dalam melakukan pembinaan dan peyaluran dana bergulir yang bersifat produktif kepada anggota kelompok masyarakat.
\end{abstract}

Kata Kunci : Tingkat kemiskinan, kelompok masyarakat, analisis SWOT.

\section{ABSTRACT}

The poverty reduction strategy is a priority strategy for every local government in Indonesia today with the aim of accelerating poverty alleviation towards a prosperous society. West Nusa Tenggara Province is one of the provinces whose poverty rates are still above the national average, so that various efforts to accelerate poverty alleviation are needed in order to catch up with other regions. This research is conducted on 3 community groups, namely farmers' community groups, fishermen community groups, and crafters community groups in 3 different villages in West Lombok, by conducting a SWOT analysis in order to find the right strategy to accelerate poverty alleviation, especially in the district of West Lombok.

The results of the study found that strategies are needed to overcome the weaknesses that exist in community groups, to get opportunities for community empowerment that exists. Programs that need to be carried out are group capacity building programs through mentoring to get empowerment programs by the government, group capacity building programs to gain banking access to increase group venture capital, and community group institutional strengthening programs by making the community groups as cooperatives with legal entities to facilitate the government in providing guidance and distribution of productive revolving funds to members of community groups.

Keywords: Poverty rate, community groups, SWOT analysis 


\section{PENDAHULUAN}

\section{Latar Belakang}

Kemiskinan merupakan masalah sosial yang dihadapi oleh hampir setiap negara di dunia, problem kemanusiaan yang menghambat kesejahteraan dan peradaban, dan semua negara di dunia sepakat bahwa program penanggulangan kemiskinan adalah program yang wajib dilakukan agar penduduk miskin semakin berkurang jumlahnya.Penduduk miskin adalah penduduk yang memiliki rata-rata pengeluaran di bawah garis kemiskinan (Badan Pusat Statistik Indonesia, 2019).Garis kemiskinan, dapat dilihat dari dua aspek, yaitu garis kemiskinan makanan (the food poverty line) dan garis kemiskinan non makanan (the non food poverty line).

Program penanggulangan kemiskinan yang dilakukan oleh pemerintah Indonesia merupakan program pembangunan berkelanjutan untuk mewujudkan masyarakat Indonesia yang semakin sejahtera dari waktu ke waktu. Hal ini sejalan dengan tujuan pembangunan milenium (MDG's - millenium development goals), yang menempatkan penanggulangan kemiskinan dan kelaparan menjadi salah tujuan prioritas, disamping tujuan-tujuan lain yang terkait dengan isu-isu mendasar tentang pemenuhan hak azasi dan kebebasan manusia, perdamaian, keamanan dan pembangunan.

Indonesia sebagai negara kepulauan yang relatif luas, terdiri dari 34 daerah propinsi memprioritaskan program penanggulangan kemiskinan bagi program pembangunan di setiap daerahnya. Hal ini bertujuan untuk menjamin terpenuhinya tingkat kesejahteraan penduduk yang relatif merata di semua wilayah Indonesia.Kondisi daerah yang berbeda-beda, khususnya dilihat dari sumberdaya yang dimiliki pada masingmasing daerah merupakan tantangan bagi pihak pemerintah daerah untuk menjalankan program penurunan kemiskinan agar sejalan dengan program pemerintah pusat.

Secara garis besar, pelaksanaan program penanggulangan kemiskinan di Indonesia dapat diidentifikasi melalui tiga jalur, yaitu jalur pembangunan sektoral, regional dan khusus. Masing-masing jalur mengandung berbagai macam pelaksanaan program yang sesuai dengan kategori program penanggulangan kemiskinan. Namun implementasi masing-masing program kadang-kadang belum sinergi dan sering tumpang tindih satu sama lain dan kurang terfokus dalam menetapkan sasaran program; siapa, apa, dimana dan bagaimana. (Komite Penanggulangan Kemiskinan, 2003: 7)

Propinsi Nusa Tenggara Barat, sebagai salah satu wilayah administratif Indonesia dalam melaksanakan program penanggulangan kemiskinan, melakukan berbagai upaya dan pendekatan melalui kebijakankebijakan yang dituangkan dalam berbagai sektor pembangunan, mengingat persentase tingkat kemiskinan penduduk di wilayah Nusa Tenggara Barat relatif lebih tinggi dibandingkan persentase kemiskinan penduduk secara nasional. Persentase penduduk miskin yang relatif tinggi berpengaruh terhadap semua aspek kehidupan masyarakat.

Tabel 1 berikut memperlihatkan perbandingan persentase penduduk miskin secara nasional dengan persentase penduduk miskin di Propinsi Nusa Tenggara Barat, selama 5 tahun terakhir.

\section{Tabel 1. Perbandingan Persentase Penduduk Miskin Tahun 2014 - 2018 , Indonesia dan Propinsi Nusa Tenggara Barat.}

\begin{tabular}{|l|c|c|c|}
\hline Tahun & Bulan & Indonesia $(\%)$ & $\begin{array}{c}\text { NusaTenggara Barat } \\
(\text { NTB })(\%)\end{array}$ \\
\hline 2011 & Maret - September & $12.49-12.36$ & $19.73-19.67$ \\
\hline 2012 & Maret - September & $11.96-11.66$ & $18.63-18.02$ \\
\hline 2013 & Maret - September & $11.37-11.47$ & $17.97-17.25$ \\
\hline 2014 & Maret - September & $11.25-10.96$ & $17.25-17.05$ \\
\hline 2015 & Maret - September & $11.22-11.13$ & $17.10-16.54$ \\
\hline 2016 & Maret - September & $10.86-10.70$ & $16.48-16.02$ \\
\hline 2017 & Maret - September & $10.64-10.12$ & $16.07-15.05$ \\
\hline 2018 & Maret - September & $9.82-9.66$ & $13.72-13.69$ \\
\hline
\end{tabular}

Sumber : 1. Statistik Indonesia, 2019, 2 Badan Pusat Statistik Nusa Tenggara Barat, 2019

Dilihat pada data di atas, ternyata bahwa tingkat persentase kemiskinan di Propinsi Nusa Tenggara Barat berada di atas tingkat kemiskinan secara nasional, di mana selama 8 tahun terakhir program penurunan 
kemiskinan di Propinsi Nusa Tenggara Barat belum bisa mengejar persentase kemiskinan nasional yang sudah di bawah $10 \%$. Namun demikian, program penurunan kemiskinan yang dilaksanakan di Propinsi Nusa Teggara Barat memperlihatkan trend yang lebih progresif dibandingkan trend penurunan kemiskinan secara nasional, sehingga dalam beberapa tahun ke depan, persentase masyarakat miskin di Propinsi Nusa Tenggara Barat diharapkan dapat menyamai persentase kemiskinan secara nasional, bahkan kalau bisa lebih rendah dibandingkan rata-rata nasional. Tentu hal ini merupakan tantangan bagi pemerintah daerah Propinsi Nusa Tenggara Barat untuk menyusun program-program penurunan kemiskinan yang lebih progresif, meliputi semua aspek kehidupan masyarakat, khususnya aspek social ekonominya, sehingga Propinsi Nusa Tenggara Barat bisa menjadi propinsi yang sejajar dengan propinsi lainnya di Indonesia.

Secara umum, program penurunan kemiskinan masyarakat di wilayah Propinsi Nusa Tenggara Barat dilaksanakan melalui program-program yang menyasar kelompok-kelompok masyarakat, melalui lembagalembaga pemerintah atau dinas-dinas Satuan Kerja Perangkat Daerah (SKPD) di bawah koordinasi Gubernur maupun Bupati, secara terintegrasi mencakup berbagai sektor pembangunan yang ditujukan kepada peningkatan kesejahteraan masyarakat.

\section{Rumusan Masalah}

Bagaimanakah strategi mempercepat penurunan tingkat kemiskinan melalui peningkatan kapasitas kelompok masyarakat dalam upaya pengentasan kemiskinan di Propinsi Nusa Tenggara Barat".

\section{Tujuan dan Manfaat Penelitian}

Penelitian ini bertujuan untuk mengidentifikasi strategi yang dapat digunakan untuk mempercepat penurunan tingkat kemiskinan melalui peningkatan kapasitas kelompok masyarakat di Propinsi Nusa Tenggara Barat. Manfaat dari penelitian ini diharapkan dapat digunakan sebagai bahan masukan bagi pihak pengambil keputusan, khususnya di bidang pengentasan kemiskinan di Propinsi Nusa Tenggara Barat.

\section{METODE PENELITIAN}

Metodelogi penelitian ini sesuai dengan permasalahan yang ingin dipecahkan adalah metode deskriptif, yaitu penelitian yang tertuju pada penggambaran suatu masalah yang ada pada waktu sekarang berdasar pada cara pengumpulan data, menyusunnya, menjelaskannya, menganalisis dan menarik kesimpulan (Surakhmad, 2002, 139). Secara praktis penelitian ini dilakukan melalui pengumpulan dan eksplorasi data primer dan sekunder yang bersumber dari beberapa sumber seperti kelompok-kelompok masyarakat yang terbentuk terkait dengan program-program pemerintah dalam rangka program pengentasan kemiskinan, datadata publikasi yang relevan yang dipublikasikan oleh Badan Pusat Statistik Propinsi Nusa Tenggara Barat dan sumber pustaka lain yang relevan.

Metode sampling menggunakan non probability sampling dengan teknik purposive, dimana syarat sampel adalah Kelompok Tani dan Ternak, Kelompok Nelayan dan Kelompok Perajin yang relevan sebagai sasaran program pengentasan kemiskinan. Pengambilan sampel secara proporsional pada masingmasing wilayah, disesuaikan dengan keperluan. Jumlah sampel yang diambil adalah sebanyak 3 kelompok masyarakat pada masing-masing kualifikasi.

Lokasi penelitian untuk kelompok masyarakat adalah wilayah Kabupaten Lombok Barat dengan memilih tiga lokasi yaitu Kelompok Tani dan Ternak di desa Suranadi, Kelompok Nelayan di Desa Lembar dan Kelompok Perajin Tenun di Desa Giri Tembesi.

Data akan dianalisis menggunakan analisis SWOT, untuk mmenentukan kekuatan dan kelemahan yang dimiliki oleh masing-masing kelompok terkait dengan fasilitasi pemerintah dalam merespon programprogram pengentasan kemiskinan, serta peluang dan tantangan yang dihadapi dalam mencapai tujuan program yang ditargetkan oleh pemerintah. Dari analisis SWOT diharapkan dapat diidentifikasi strategi yang sesuai untuk diterapkan dalam mempercepat tujuan program pengentasan kemiskinan yang dicanangkan oleh pemerintah, khususnya Pemerintah Kbupaten Lombok Barat. Pembahasan dilakukan secara naratif, dengan menganalisis tabel silang (crosstab analysis) berupa data matriks SWOT yang dihasilkan dari analisis SWOT, sehingga ditemukan suatu solusi atau model yang terkait dengan tujuan penelitian ini. 


\section{HASIL DAN PEMBAHASAN}

Penyusunan alternatif model penanggulangan kemiskinan bagi masyarakat di daerah penelitian memerlukan adanya analisis lingkungan, berupa analisis lingkungan internal dan lingkungan eksternal yang dikenal dengan analisis SWOT. Hasil penggalian informasi yang diperoleh dari responden penelitin yang dilakukan melalui wawancara mendalam serta pengamatan lapangan dianggap memadai sebagai bahan untuk melakukan analisis SWOT untuk menemukan strategi dan model program penanggulangan kemiskinan bagi kelompok-kelompok masyarakat di daerah penelitian. Analisis SWOT diterapkan berdasarkan hasil penilaian aspek-aspek lingkungan internal dan eksternal, dengan membuat bobot dan skor setiap aspek yang telah dinilai, untuk menentukan nilai setiap indikator yang ada, melalui tabel EFAS (external factor analysis summary) dan IFAS (internal factor analysis summary).

\section{Analisis Lingkungan Internal}

\section{Kekuatan}

a. Kelompok masyarakat, baik kelompok tani, kelompok nelayan maupun kelompok peajin merupakan lembaga yang diakui oleh pemerintah maupun pihak-pihak lainnya. Kelompok masyarakat ini merupakan wadah bagi masyarakat, khususnya dalam mendapatkan program-program pemberdayaan untuk masyarakat.

b. Memiliki semangat yang tinggi dan rasa gotong royong di antara anggota kelompok maupun antar kelompok masyarakat.

c. Berpengalaman dalam menekuni bidang pekerjaannya karena mereka terhimpun dalam suatu kelompok dengan profesi yang sama.

d. Rasa setia kawan di antara sesama anggota kelompok menjadikan mereka selalu menjalin komunikasi dan bekerjasama dalam mengatasi berbagai masalah dan kendala yang dihadapi.

\section{Kelemahan}

a. Kemampuan ekonomi yang rendah/modal terbatas, tidak memiliki tabungan.Hal ini terjadi karena kondisi pendapatan petani, nelayan maupun perajin rumah tenun yang tidak menentu, pendapatan hanya diperoleh jika mereka bekerja, dan sifatnya harian.Tidak ada bagian pendapatan yang diperoleh yang digunakan untuk menabung.

b. Kelompok masyarakat ini pada umumnya belum meiliki badan hukum sehingga menyulitkan kelompok untuk mengakses sumber permodalan untuk mengembangkan diri, selain menunggu bantuan pemerintah.

c. Kontinyuitas kelompok tidak bisa bertahan, jika tidak ada program-program pemerintah yang menyasar kelompok masyarakat tersebut.

d. Konflik antar anggota kelompok sering terjadi terutama mengenai masalah kepemilikan alat yang merupakan bantuan pemerintah, seperti banguan perahu, bantuan peralatan mesin produksi, dan lain-lain.

e. Keterampilan anggota kelompok terbatas pada bidang pekerjaan yang ditekuni, terutama pada kelompok nelayan, selain sebagai nelayan mereka tidak memiliki keterampilan lainnya sehingga ketika cuaca yang ekstrim datang nelayan tidak bisa melaut, otomatis mereka tidak memiliki pekerjaan dan tidak dapat menghasilkan pendapatan.

\section{Analisis Lingkungan Eksternal}

\section{Peluang}

a. Kelompok masyarakat merupakan sasaran utama bagipenyaluran program-program pemerintah, terutama program pemberdayaan yang bertujuan untuk mempercepat pengentasan kemiskinan.

b. Kelompok-kelompok masyarakat bisa ditingkatkan statusnya dengan melengkapi badan hokum, sehingga kelompok masyarakat ini menjadi lembaga formal yang dapat mengakses banyak pihak, dalam rangka meingkatkan kesejahteraan anggota kelompok.

c. Adanya berbagai program pemberdayaan masyarakat,baik itu masyarakat petani, petrnak,nelayan maupun perajin industry rumah tangga dengan dukungan pemerintah yang intens dan berkelanjutan untuk terus menekan angka kemiskinan, khususnya bagi masyarakat berpenghasilan rendah.

d. Pembentukan koperasi yang berasal dari kelompok-kelompok masyarakat merupakan salah satu alternative untuk memecahkan permasalahan permodalan yang terbatas sehingga melalui koperasi kelompok masyarakat ini, pemerintah dapat menyalurkan dana bergulir, sebagai modal dengan bunga yang ringan untuk meningkatkan produktivitas kerja kelompok masyarakat.

e. Mendapatkan pendampingan, yaitu peluang-peluang yang juga disediakan oleh pemerintah dengan menyiapkan tanaga-tenaga penyuluh di bidang pertanian, perikanan, perajin industry rumah tangga, 
pendampingan dalam mengelola bantuan yang diberikan dan bentuk-bentuk pendampingan lain yang tujuannya untuk meningkatkan kesejahteraan masyarakat.

\section{Tantangan}

a. Perkembangan teknologi yang semakin pesat menyebabkan persaingan di segala bidang semakin ketat sehingga kelompok-kelompok masyarakat ini juga harus melek teknologi.

b. Kelompok-kelompok masyarakat ini dituntuk unuk terus mengembangkan inovasi, kreativitas dan produktivitas agar bisa meraih peluang-peluang global yang semakin terbuka.

c. Arus globalisasi yang semakin menjangkau seluruh lapisan masyarakat, agar selalu meningkatkan kualitas diri, sehingga kapasitas kelompok masyarakat juga agar terus ditingkatkan.

d. Tuntutan peningkatan kualitas sumber daya manusia yang semakin meningkat dalam era globalisasi mengharuskan setiap kelompok masyarakat yang ingin tetap eksis harus selalu meningkatkan kualitas diri baik anggota maupun kelembagaannya.

Dari analisis SWOT di atas, kemudian dilakukan suatu pembobotan terhadap setiap aspek yang dinilai, baik pada analisis lingkungan internal maupun analisis lingkungan eksternal. Tabel IFAS dan EFAS memberikan gambaran dari hasil penilaian faktor lingkungan internal dan eksternal, seperti pada tabel 2 dan 3berikut :

Tabel 2 :Identifikasi Analisis Lingkungan Internal Terhadap Kelompok masyarakat di daerah Penelitian

\begin{tabular}{|l|l|l|l|}
\hline FAKTOR-FAKTOR LINGKUNGAN INTERNAL & BOBOT & RATING & $\begin{array}{l}\text { BOBOT x } \\
\text { RATING }\end{array}$ \\
\hline $\begin{array}{l}\text { KEKUATAN : } \\
\text { 1. Memiliki kelompok sebagai wadah dalam menerima } \\
\text { program-program pemerintah }\end{array}$ & 0,12 & 3 & 0,36 \\
$\begin{array}{l}\text { 2. Memiliki semangat yang tinggi dan rasa gotong royong di } \\
\text { antara anggota kelompok maupun antar kelompok nelayan }\end{array}$ & 0,10 & 3 & 0,30 \\
$\begin{array}{l}\text { 3. Berpengalaman dalam menekuni pekerjaan dengan profesi } \\
\text { yang sama }\end{array}$ & 0,12 & 2 & 0,24 \\
4. Rasa setia kawan di antara sesama anggota kelompok. & 0,11 & 2 & 0,22 \\
\hline $\begin{array}{l}\text { KELEMAHAN: } \\
\text { 1. Kemampuan ekonomi yang rendah/modal terbatas }\end{array}$ & 0,12 & -3 & $-0,36$ \\
$\begin{array}{l}\text { 2. Belum memiliki badan hokum sehingga sulit mengakses } \\
\text { sumber permodalan }\end{array}$ & 0,10 & -2 & $-0,20$ \\
3. Kontinyuitas kelompok tidak terjamin, karena dibentuk \\
$\quad$ saat ada program bantuan pemerintah
\end{tabular}

Sumber : Hasil Wawancara dan Pengamatan Lapangan

Posisi strategis dari identifikasi lingkungan internal bernilai negatif - 0,21 yang berarti bahwa kondisi pada faktor internal termasuk lemah.

Tabel 3 :Identifikasi Analisis Lingkungan Eksternal Terhadap Kelompok Masyarakat di daerah Penelitian

\begin{tabular}{|c|c|c|c|}
\hline FAKTOR-FAKTOR LINGKUNGAN EKSTERNAL & BOBOT & RATING & $\begin{array}{l}\text { BOBOT } x \\
\text { RATING }\end{array}$ \\
\hline \multicolumn{4}{|l|}{ PELUANG : } \\
\hline $\begin{array}{l}\text { 1. Kelompok masyarakat merupakan sasaran utama program } \\
\text { pemberdayaan oleh pemerintah }\end{array}$ & 0,10 & 3 & 0,30 \\
\hline $\begin{array}{l}\text { 2. Kelompok masyarakat bisa melengkapi badan hukum agar } \\
\text { terbuka lebih banyak akses }\end{array}$ & 0,12 & 3 & 0,36 \\
\hline $\begin{array}{l}\text { 3. Adanya berbagai program pemberdayaan bagi kelompok- } \\
\text { kelompok masyarakat. }\end{array}$ & 0,10 & 3 & 0,30 \\
\hline 4. Pembentukan koperasi dari kelompok masyarakat & 0,13 & 3 & 0,39 \\
\hline 5. Mendapatkan pendampingan & 0,11 & 3 & 0,33 \\
\hline \multicolumn{4}{|l|}{ TANTANGAN: } \\
\hline 1. Perkembangan teknologi semakin pesat & 0,12 & -3 & $-0,36$ \\
\hline 2. Tuntutan peningkatan kreativitas, inovasi dan produktivitas & 0,11 & -3 & $-0,33$ \\
\hline 3. Arus globalisasi yang menjangkau semua lapisan & 0,10 & -2 & $-0,20$ \\
\hline 4. Peningkatan Sumber Daya Manusia & 0,11 & -2 & $-0,22$ \\
\hline Total & 1,00 & & 0,57 \\
\hline
\end{tabular}

Sumber : Hasil Wawancara dan Pengamatan Lapangan 
Posisi strategis dari identifikasi pada lingkungan eksternal menunjukkan nilai positip yaitu 0,57 , yang berarti bahwa peluang yang ada lebih besar dibandingkan dengan tantangan yang dihadapi.

\section{Posisi Strategis Kelompok Masyarakat}

Untuk mendapat gambaran tentang posisi strategis dari kelompok masyarakat di daerah penelitian, kedua hasil evaluasi tersebut selanjutnya akan dituangkan ke dalam diagram analisis SWOT. Nilai evaluasi lingkungan internal menunjukkan nilai negatif (lemah) sebesar - 0,21 berada pada posisi ke arah kiri dari skala kekuatan dan kelemahan, dan nilai evaluasi lingkungan eksternal sebesar 0,57 menunjukkan nilai positip, yaitu ke arah atas pada sumbu peluang dan ancaman. Jika ditarik garis yang menghubungkan absis dan ordinat kedua nilai tersebut, maka posisi strategis kelompok nelayan di ketiga daerah penelitian, seperti terlihat pada Gambar 2 berikut :

Gambar 2 :Posisi Strategis Kelompok Masyarakat di Daerah Penelitian berdasarkan Analisis SWOT,

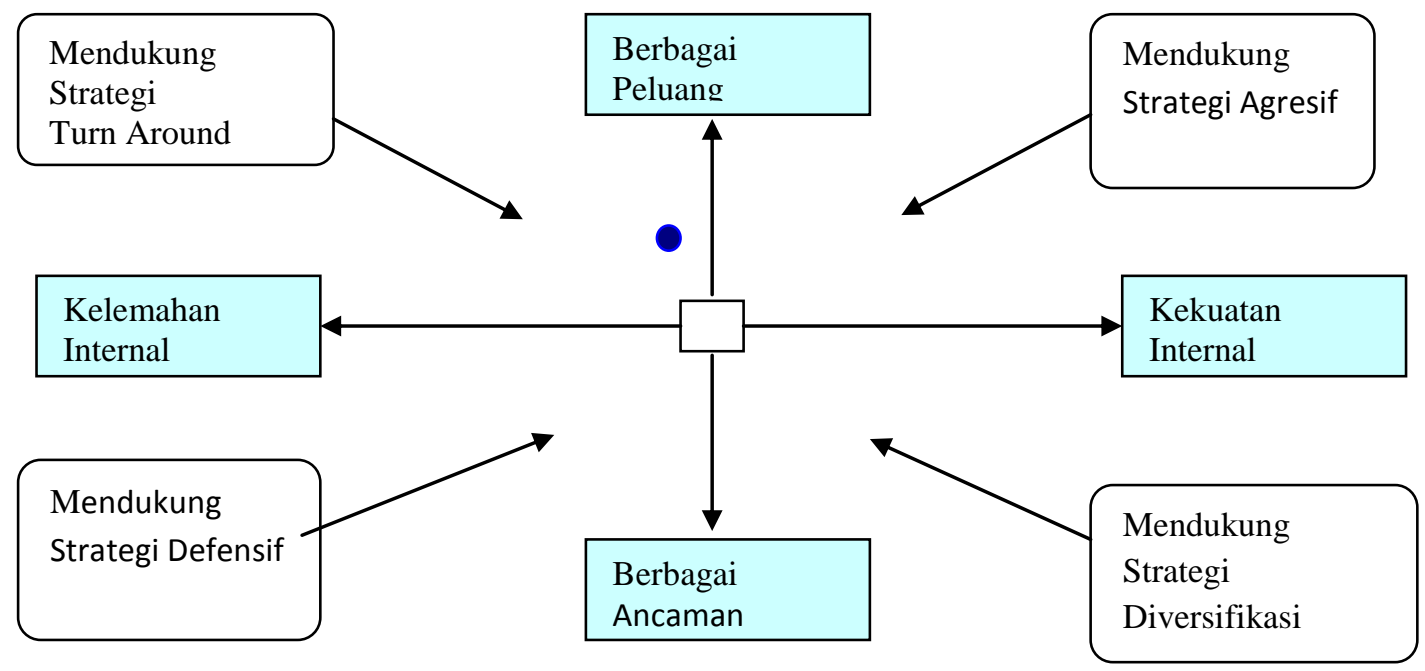

Sumber : Data Primer, diolah.

Keterangan : = Tanda Posisi Strategis Kelompok Nelayan

Dengan melihat posisi strategis dari hasil evaluasi lingkungan internal dan lingkungan eksternal, maka posisi strategik kelompok nelayan berada pada kuadran yang mendukung strategi turn around, yaitu menanggulangi kelemahan yang dimiliki untuk dapat meraih peluang-peluang yang ada.

Sesuai dengan diagram SWOT yang dihasilkan di atas, maka strategi, program dan sasaran yang dapat dirumuskan terkait dengan strategi penanggulangan kemiskinan pada masyarakat pesisir, khususnya di daerah penelitian seperti pada tabel 4 .

\section{Tabel 4 : Strategi, Program dan Sasaran Hasil Analisis SWOT bagi Kelompok Masyarakat di daerah Penelitian, tahun 2019.}

\begin{tabular}{|c|c|c|}
\hline Strategi & Program & Sasaran \\
\hline $\begin{array}{ll}\text { Strategi } & \text { WO }\end{array}$ & & \\
\hline $\begin{array}{l}\text { Tanggulangi kelemahan } \\
\text { yang di-miliki untuk } \\
\text { menang-kap peluang yang } \\
\text { ada }\end{array}$ & $\begin{array}{l}\text { - Peningkatan kapasitas kelompok } \\
\text { masyarakat melalui program } \\
\text { pendampingan dan bim-bingan } \\
\text { dalam mendapatkan bantuan } \\
\text { pemerintah. } \\
\text { - Peningkatan kapasitas ke-lompok } \\
\text { masyarakat dalam mengakses } \\
\text { perbankan atau sumber } \\
\text { permodalan. } \\
\text { - Peningkatan kapasitas kelompok } \\
\text { masyarakat menjadi Koperasi } \\
\text { yang berbadan hukum }\end{array}$ & $\begin{array}{l}\text { - Kelompok masyarakat bisa meng-akses } \\
\text { dengan baik program pemberdaya-an } \\
\text { yang dilaksanakan oleh pemerintah } \\
\text { - Memudahkan mendapatkan modal oleh } \\
\text { masyarakat melalui kelompok } \\
\text { masyarakat yang ada, dengan bunga } \\
\text { yang wajar } \\
\text { - Memudahkan penyaluran dana bergulir } \\
\text { oleh pemerintah melalui koperasi } \\
\text { kelompok masyarakat binaan. }\end{array}$ \\
\hline
\end{tabular}




\section{SIMPULAN DAN SARAN}

\section{Simpulan}

Dari pembahasan di atas, sesuai dengan permasalahan yang ingin dipecahkan, maka dapat disimpulkan bahwa strategi yang digunakan dalam mempercepat penurunan tingkat kemiskinan adalah strategi menanggulangi kelemahan pada kelompok masyarakat untuk meraih peluang-peluang yang ada dalam memberdayakan masyarakat.

\section{Saran}

Bagi pihak pemerintah daerah, khususnya Pemerintah daerah Lombok Barat, disarankan untuk melakukan pembinaan terhadap kelompok-kelompok masyarakat, khususnya masyarakat petani, peternak, nelayan dan perajin, sebagai berikut :

1. Melakukan peningkatan kapasitas kelompok masyarakat melalui program pendampingan agar dapat mengakses bantuan program pemberdayaan masyarakat dengan lebih mudah

2. Program Peningkatan kapasitas kelompok masyarakat untuk akses perbankan, agar dapat meningkatkan produktivitas dengan tambahan modal usaha dari pihak perbankan

3. Meningkatkan kapasitas kelompok masyarakat menjadi koperasi kelompok masyaraat yang berbadan hokum agar pemerintah lebih mudah untuk menyalurkan dana bergulir bagi kepentingan usaha produktif masyarakat.

\section{DAFTAR PUSTAKA}

Anonimous, 2003, Buku Pedoman Komite Penanggulangan Kemiskinan Tahun 2003, Komite Penanggulangan Kemiskinan, Jakarta

BPS NTB, 2018, Capaian Pembangunan NTB Dalam Guratan Data, Badan Pusat Statistik Propinsi Nusa Tenggara Barat Mataram

BPS NTB, 2019, Nusa Tenggara Barat Dalam Angka, badan Pusat Statistik Propinsi Nusa Tenggara Barat. Kuncoro,M, 2010. Dasar-dasar Ekonomika Pembangunan, Penerbit: UPP STIM YKPN Yogyakarta. Siswanto, Budi, 2008, Kemiskinan dan Perlawanan Kaum Nelayan, Laksbang Mediatama, Surabaya.

Sugiyono, 2014. Metode. Penelitian Pendidikan, Pendekatan Kuantitatif, Kualitatif dan R\&D, Penerbit Alfabeta Bandung.

Surakhmad, Winarno, 2002 Metode Penelitian, Penerbit Tarsito, Bandung.

Suyanto, Bagong, 2013. Anatomi Kemiskinan, Dan Strategi Penanganannya, (Fakta Kemiskinan Masyarakat Pesisir, Kepulauan, Perkotaan dan Dampak dari Pembangunan di Indonesia), Intrans Publishing, Malang. 